\title{
Del Estado Novo al Nuevo Estado: música, prensa y propaganda en las relaciones entre Portugal y Sevilla durante la Guerra Civil española
}

\author{
From the Estado Novo to the Nuevo Estado: Music, \\ Press and Propaganda in the Relations between \\ Portugal and Seville during the Spanish Civil War
}

El presente artículo se centra en las relaciones musicales establecidas durante la Guerra Civil española entre el Estado Novo de Antonio de Oliveira Salazar y Sevilla, ciudad que fue tomada por el bando sublevado desde el inicio de este conflicto bélico que acabó no solo con la vida de cientos de miles de personas, sino también con formas de cultura, pensamiento e ideologías que fueron drásticamente sustituidas por las que imponía el Nuevo Estado. En los años que duró el conflicto, tanto en Portugal como en la capital andaluza tuvieron lugar una serie de iniciativas que serán analizadas por el papel fundamental que desempeñó la música en la creación de vínculos de amistad entre la dictadura salazarista y el nuevo Régimen franquista que se estaba configurando.

Palabras clave: Sevilla, Andalucía, Portugal, Guerra Civil, franquismo, música y política, prensa.

The present article focuses on the musical relations established during the Spanish Civil War between Antonio de Oliveira Salazar's Estado Novo and Seville. The Spanish city was captured by the Nationalist faction at the beginning of the military conflict that not only wiped out hundreds of thousands of people, but forms of culture, ways of thinking and ideologies that were drastically replaced by those imposed by the Nuevo Estado. During the conflict, a series of initiatives were put into place in both Portugal and the Andalusian capital that will be analysed by examining the fundamental role that music played in the creation of bonds of friendship between the Salazar dictatorship and the new Franco Regime that was taking shape.

Keywords: Seville, Andalusia, Portugal, Spanish Civil War, Francoism, music and politics, press.

\section{Introducción}

La influencia decisiva del panorama político internacional de la segunda mitad de la década de 1930 en el desarrollo de la Guerra Civil española es de sobra conocida. La ayuda ítalo-germana permitió introducir el ejército de África en la Península, mientras que el apoyo militar de la Unión Soviética al bando republicano sirvió como pretexto a las potencias del Eje para incrementar su apoyo financiero y militar al bando sublevado. A finales de julio, cuando el gobierno francés del Frente Popular descubrió que los nazis alemanes y fascistas italianos estaban ayudando al bando franquista, surgió la 
iniciativa del “Acuerdo de No Intervención”, por el que todos los estados europeos -excepto Suiza, que no se adhirió al pacto- se comprometían a abstenerse de participar en este conflicto bélico, prohibiéndose la exportación de toda clase de armas, municiones y material de guerra. Sin embargo, los apoyos iniciales se mantuvieron casi inalterables hasta el final del enfrentamiento, de forma que Alemania, Italia y Portugal se burlaron sistemáticamente de este acuerdo, que acabó convirtiéndose en una auténtica farsa ${ }^{1}$.

Historiadores como César Oliveira o Hipólito de la Torre Gómez han estudiado en profundidad las dificiles y complejas relaciones entre ambos países durante el siglo $\mathrm{XX}^{2}$. Gracias a estas aportaciones se sabe que, durante el primer tercio del siglo, la "fractura peninsular" se fue abriendo progresivamente hasta llegar a posiciones antagónicas e irreconciliables tras la proclamación de la Segunda República española ${ }^{3}$. A partir de este momento, tuvo lugar un acusado distanciamiento entre ambos países pues el nuevo régimen político de España suponía una seria advertencia para el aún no consolidado Estado Novo de António de Oliveira Salazar ${ }^{4}$. Por ello, la prensa lusa, fuertemente controlada por el régimen, inició una guerra propagandística contra su vecina republicana que sólo se calmó durante el bienio radical-cedista (1933-1936), alcanzando su punto más crítico durante el gobierno del Frente Popular ${ }^{5}$. En este contexto, el dictador portugués no dudó en colaborar con los opositores al Estado español, conociendo y consintiendo el tránsito por Lisboa de agentes al servicio de Emilio Mola y José Sanjurjo, y deseando el éxito del Alzamiento por el bien de su propia dictadura ${ }^{6}$.

\footnotetext{
${ }^{1}$ Véase Julián Casanova: República y Guerra Civil, Madrid, Crítica, 2007, pp. 261-266.

2 Véase C. Oliveira: Portugal e a II República de Espanha (1931-1936), Lisboa, Perspectivas \& Realidades, 1985; id.: Salazar e a Guerra Civil de Espanha, Lisboa, Edições O Jornal, 1987; id: Cem Anos nas Relações Luso-Espanholas. Política e Economia, Lisboa, Edições Cosmos, 1995; H. de la Torre Gómez: La relación peninsular en la antecámara de la Guerra Civil (1931-1936), Mérida, UNED-Centro Regional de Extremadura, 1988; id.: Do perigo español à amizade peninsular: Espanha-Portugal (1919-1930), Lisboa, Estampa, 1985; H. de la Torre Gómez y Josep Sánchez Cervelló: Portugal en el siglo XX, Madrid, Istmo, 1992.

3 Esta idea se desarrolla en H. de la Torre Gómez: Antagonismo y fractura peninsular: España-Portugal (1910-1919), Madrid, Espasa-Calpe, 1983.

${ }^{4}$ La República Española suponía una amenaza para el salazarismo tanto por las influencias indirectas que podía tener sobre el movimiento republicano portugués, como por la conspiración de los propios exiliados en territorio español y francés. De hecho, el gobierno luso conocía que el último presidente de la República portuguesa, Afonso Costa, y los miembros de la "Liga de París" estaban en contacto con el gobierno español. Véase C. Oliveira: Salazar e a Guerra Civil de Espanha..., pp. 75 y ss.

${ }^{5}$ En el inicio de la Segunda República Española ya funcionaba sobre la prensa portuguesa una censura completamente legislada e institucionalizada que, gracias a sus intensas campañas de desinformación, se convirtió en un poderoso cómplice del gobierno autoritario luso. Véase C. Oliveira: Portugal e a II República de Espanha..., pp. 82-105; Alberto Pena Rodríguez: O que parece é: Salazar, Franco e a propaganda contra a Espanha democrática, Lisboa, Tinta da China, 2009; id.: Galicia, Franco y Salazar: la emigración gallega en Portugal y el intercambio ideológico entre el franquismo y el salazarismo, Vigo, Universidade de Vigo, 1999, pp. 26 y ss.

${ }^{6}$ A. Pena Rodríguez: Galicia, Franco y Salazar..., p. 29.
} 
Una vez iniciada la contienda, e ignorando el citado "Acuerdo de No Intervención", la ayuda de Portugal fue decisiva, pues ofreció al bando sublevado una base de operaciones para la compra de armas, la devolución a la España sublevada de todos los republicanos que huían de la represión y la utilización de carreteras, puertos y ferrocarriles para comunicar la zona noroccidental con Andalucía.Además, el dictador portugués defendió la causa rebelde en el Comité de No Intervención, en la Sociedad de Naciones y en otros foros internacionales 7 . Por otra parte, se ha de señalar la influencia de Nicolás Franco, hermano del Caudillo y embajador de España en Lisboa, que realizó una gran campaña de propaganda a favor del bando franquista desde Portugal ${ }^{8}$.

En los últimos años se han llevado a cabo varios estudios sobre los intercambios musicales de la España franquista con dos de estos regímenes totalitarios -el nazismo alemán y el fascismo italiano-, que ponen de manifiesto que estos países no solo prestaron su ayuda militar y económica durante la Guerra Civil, sino que en ocasiones se convirtieron también en modelos del empleo del arte y la música como instrumentos de propaganda, propiciando así intensos contactos culturales e intercambios musicales 9 . No obstante, dentro de la inagotable historiografía sobre el conflicto bélico, pocos han estudiado en profundidad el papel de la propaganda política y la música en la dictadura salazarista ${ }^{10}$. De hecho, en el terreno puramente musical, a diferencia de lo acontecido con respecto a otras naciones amigas, ha habido que esperar hasta 2013 para que vea la luz una publicación sobre los intercambios musicales entre España y Portugal, venida de la mano de Contreras Zubillaga y Deniz Silva, centrada en los primeros años del franquismo ${ }^{11}$.

\footnotetext{
7 J. Casanova: República y Guerra Civil..., p. 269.

${ }^{8}$ A. Pena Rodríguez: Galicia, Franco y Salazar..., pp. 125-126.

${ }^{9}$ Véase Erik Levi: "The Reception of Spanish Music in Germany during the Nazi Era", Music and Francoism, Gemma Pérez Zalduondo y Germán Gan Quesada (eds.), Turnhout, Brepols, 2013, pp. 324; Javier Suárez-Pajares: "Festivals and Orchestras. Nazi Musical Propaganda in Spain during the Early 1940s", Music and Francoism..., pp. 59-95; Beatriz Martínez del Fresno: "La sección femenina de la falange y sus relaciones con los países amigos: Música, danza y política exterior durante la Guerra y el primer franquismo (1937-1943)", Cruces de caminos: intercambios musicales y artísticos en la Europa de la primera mitad del siglo XX, Gemma Pérez Zalduondo y María Isabel Cabrera García (eds.), Granada, Editorial Universidad de Granada, 2010, pp. 357-406; G. Pérez Zalduondo: "La música en los intercambios culturales entre España y Alemania (1938-1942)", Cruces de caminos..., pp. 407-452; Eva Moreda Rodríguez: "Fascist Spain and the Axis: Music, Politics, Race and Canon", British Postgraduate Musicology, 9, 02/2008. Disponible en: http://britishpostgraduatemusicology.org/ bpm9/rodriguez.html (última consulta: 11-12-2015); id.: "Italian Musicians in Francoist Spain, 1939-1945: The Perspective of Music Critics", Music and Politics, 2, 1, 2008 (http://quod.lib.umich.edu/m/mp/9460447. 0002.105/_ italian-musicians-in-francoist-spain-1939-1945?rgn=main;view=fulltext (última consulta: 11-12-2015); G. Pérez Zalduondo: "Música y músicos Italianos en España (1931-1943)", Italian Music during the Fascist Period, Roberto Illiano (ed.), Turnhout, Brepols, 2004, pp. 65-94.

${ }^{10}$ A. Pena Rodríguez: Galicia, Franco y Salazar..., p. 16.

${ }^{11}$ Igor Contreras Zubillaga y Manuel Deniz Silva, Manuel: “'Obligados a convivir pared con pared'. Los intercambios musicales entre España y Portugal durante los primeros años del Franquismo (19391944)", Music and Francoism..., pp. 25-57.
} 
Por tanto, se ha considerado de interés el estudio de las relaciones musicales que tuvieron lugar entre Portugal y España durante la Guerra Civil española. En concreto, esta investigación se centrará en una importante ciudad de la retaguardia nacionalista: Sevilla, cuya elección viene motivada por dos razones. En primer lugar, por tratarse de una ciudad con gran tradición musical, y en segundo lugar, por ser una de las más importantes capitales en posesión de los sublevados desde el inicio de la contienda. Hay que tener presente la rápida dominación y el férreo control ejercidos por Queipo de Llano en la capital andaluza, que siempre mostró fidelidad y apoyo ante las múltiples iniciativas que partían de los diferentes poderes. En palabras de Alfonso Braojos, "la muestra de lo que sería la España de Franco, lo era ya la Sevilla de Queipo", pues durante el conflicto bélico acató y asumió rápidamente todos los cambios haciéndolos suyos ${ }^{12}$.

De esta forma, se pretende profundizar en la función de estos contactos internacionales en el contexto de la política musical llevada a cabo desde los primeros años del franquismo, entendiendo el periodo bélico como un momento de transformación, construcción y definición del papel de la música en el nuevo régimen. Además, aunque acotado a un ámbito local, este estudio puede ayudar también a entender mejor la propagación de estos eventos a otras zonas tomadas por el bando nacional con posterioridad.

Para llevar a cabo la presente investigación se ha realizado un vaciado de noticias de interés musical publicadas en la prensa sevillana durante la Guerra Civil, empleando una serie de periódicos conservados en la Hemeroteca Municipal de Sevilla. Se ha de destacar la riqueza de la oferta periodística de la ciudad, ya que en esos momentos todas las familias del nuevo régimen que se estaba consolidando quedaban representadas, pues existía un diario monárquico-alfonsino $(A B C$ de Sevilla), uno carlista ( $\mathrm{La}$ Unión), uno fascista-falangista ( $F E$ ) y uno católico (El Correo de Andalucía).

A la hora de plantear un análisis de fuentes hemerográficas publicadas en la España nacional, se ha de tener en cuenta que se trata de una prensa de guerra, combativa e instrumentalizada como vehículo de propaganda, que siguió los cánones del modelo mecanicista definido por Timoteo Álvare $^{13}$. Desde los primeros momentos del Alzamiento, los sublevados se interesaron por controlar los periódicos y las radios, quedando ya establecida la censura en el 28 de julio de $1936^{14}$. El punto culminante de este

\footnotetext{
12 Alfonso Braojos, María Parias y Leandro Álvarez Rey: Sevilla en el siglo XX (1868-1950), Sevilla, Universidad de Sevilla, 1990, p. 222. Véase también pp. 213-237 de dicha monografía; y José Santotoribio Sumariba: Sevilla en la vida municipal (1920-1991), Sevilla, Editorial Gb, 1994, pp. 224-260.

13 Jesús Timoteo Álvarez: Historia y modelos de comunicación en el siglo XX. El nuevo orden informativo, Barcelona, Ariel, 1992, pp. 110-113.

14 Sobre las características de la prensa del bando nacional y del franquismo, véase Javier Terrón Montero: La prensa de España durante el régimen de Franco, Madrid, Instituto de Investigaciones
} 
proceso fue la promulgación de la Ley de Prensa del 22 de abril de 1938, basada en el decreto fascista italiano sobre prensa y, a partir de la cual, según Justino Sinova, el periodismo sería concebido como una actividad al servicio del Estado y el periódico como un instrumento de acción política ${ }^{15}$.

\section{La música en Sevilla durante la Guerra Civil española}

Tan solo unos días después de la sublevación comenzaron a celebrarse en la capital andaluza gran cantidad de eventos que mostraban una concepción utilitarista de la música, la cual pasó rápidamente a emplearse como herramienta de propaganda del nuevo régimen, con intención de captar a las masas y atraerlas hacia la ideología que este pretendía imponer ${ }^{16}$.

Por tanto, el inicio del conflicto bélico en absoluto supuso una paralización de la vida musical en la ciudad. De hecho, fueron precisamente las circunstancias bélicas del momento las que impulsaron gran parte de estos actos, destinados, por una parte, a paliar las necesidades de la guerra y agradecer la labor de los soldados y, por otra, a consolidar el nuevo Estado, queriendo vender la imagen de bienestar que se vivía en las zonas que ya habían sido tomadas por el bando sublevado, tanto dentro del país como fuera de él. En este último caso, destacan las conexiones culturales que se establecieron con la Alemania nazi, la Italia fascista y el Portugal salazarista, países con los que la España nacional consolidó lazos de amistad, y como fruto de estas interrelaciones tuvieron lugar en Sevilla diversas actividades musicales que sirvieron como actos de hermanamiento entre regímenes totalitarios ${ }^{17}$.

La ciudad continuó desarrollando su vida musical en torno a instituciones culturales como el Ateneo o la Real Academia de Bellas Artes de Santa Isabel de Hungría, la Universidad, los distintos teatros, la Catedral

Sociológicas, 1981; Justino Sinova: "La prensa franquista”, La Guerra Civil: La cultura, 17, Madrid, Historia 16, 1987; id.: La censura de prensa durante el franquismo, Madrid, Espasa Calpe, 1989; Alejandro Pizarroso Quintero: "Política informativa: Información y propaganda (1939-1966)", Historia de los medios de comunicación en España. Periodismo, imagen y publicidad (1900-1990), Barcelona, Ariel, 1989; id.: Historia de la Propaganda, Madrid, Eudema, 1990; Sara Núñez del Prado: Servicios de información y propaganda en la Guerra Civil española. 1936-1939, Madrid, Universidad Complutense, 1992; Carlos Barrera: Periodismo y franquismo. De la censura a la apertura, Pamplona, Eunsa, 1995; Francisco Sevillano Calero: Propaganda y medios de comunicación en el Franquismo (1936-1951), Alicante, Universidad de Alicante, 1998.

${ }^{15}$ Véase J. Sinova: La censura de prensa..., p. 17.

${ }^{16}$ Sobre la presencia ideológica y política de la música durante el periodo franquista véase G. Pérez Zalduondo: Una música para el Nuevo Estado. Música, ideología y política en el primer franquismo, Sevilla, Libargo, 2013; y G. Pérez Zalduondo y Germán Gan Quesada (eds.): Music and Francoism, Turnhout, Brepols Publishers, 2013.

${ }^{17}$ Para una visión más detallada, véase Olimpia García López: La música en Sevilla durante la Guerra Civil a través de la prensa, Trabajo Fin de Máster, Universidad de Granada, 2013. 
y, por supuesto, el nuevo Conservatorio Oficial de Música ${ }^{18}$. Los eventos siguieron estando protagonizados por los mismos intérpretes, a excepción de Ernesto Halffter, vinculado a la ciudad desde su nombramiento como director de la Orquesta Bética de Cámara en 1924, y nombrado director de dicho centro de enseñanzas musicales ${ }^{19}$. Encontrándose en Lisboa desde el mes de febrero, tras haber obtenido la beca "Fundación Conde de Cartagena" de la Academia de Bellas Artes de San Fernando y, a pesar de haber manifestado su adhesión al bando nacional mediante un escrito enviado a la Junta de Burgos el 30 de septiembre de 1936, fue suspendido de empleo y sueldo en noviembre de 1936, quedando separado definitivamente de su puesto en mayo de 1937. No obstante, fue readmitido en el Conservatorio hispalense en 1941, aunque, no muy entusiasmado en retomar su cargo, consiguió ser nombrado catedrático de Música y Cantos Españoles en el Instituto Español de Lisboa en 1942, puesto en el que permanecería diez años ${ }^{20}$.

Como ejemplo de su temprano posicionamiento a favor del bando sublevado puede destacarse su participación dirigiendo a la Orquesta Sinfonica da Emissora Nacional e de cantores solistas en un concierto a beneficio del ejército español que inauguró la temporada del Círculo de Cultura Musical de Lisboa en diciembre de 1936. El programa del recital, al que asistieron autoridades civiles, militares, académicas y diplomáticas, estuvo compuesto por obras del propio Halffter y de su maestro Manuel de Falla ${ }^{21}$.

\footnotetext{
18 Sobre la fundación del Conservatorio de Música de Sevilla, véase O. García López: "La recompensa a un esfuerzo colectivo: el nacimiento del Conservatorio de Música de Sevilla", Diferencias: Revista del CSM Manuel Castillo de Sevilla, 3. é época, 4, 2014, pp. 119-150.

${ }^{19}$ Ernesto Halffter fue nombrado catedrático de Contrapunto vocal e instrumental el 25 de abril de 1934, director interino el 2 de junio de 1934 y director el 2 de agosto de 1934. Véase Gaceta de Madrid, 119, 29-IV-1934, p. 702; Gaceta de Madrid, 157, 6-VI-1934, p. 1560; y Gaceta de Madrid, 217, 5VIII-1934, p. 1271.

20 Sobre la labor de Ernesto Halffter en la Guerra Civil, véase I. Contreras Zubillaga: "El eco de las batallas: música y guerra en el bando nacional durante la contienda civil española (1936-1939)", Amnis. Revue de cuvilisation contemporaine Europes/Amériques, 10, 2011, pp. 5-7. http://amnis.revues.org/1195 (última consulta: 30-5-2016); I. Contreras Zubillaga y M. Deniz Silva: “Obligados a convivir pared con pared'...", pp. 31-32, 39-41; y Y. Acker: "Ernesto Halffter (1905-1989)...", pp. 65-71. Véase también Archivo Manuel de Falla (AMF), sig. 6692-006. Carta de Norberto Almandoz a Manuel de Falla, 12 VII-1936; AMF, sig. 7098-032. Carta de Ernesto Halffter a Manuel de Falla, 26-X-1936; Archivo Vasco de la Música (Eresbil), sig. Al/L-161. Carta de Ernesto Halffter Norberto Almandoz, 26-I-1937; AMF, sig. 7098-058. Carta de Ernesto Halffter a José María Pemán, 1-III-1937; AMF, sig. 7098-061. Carta de Ernesto Halffter a Manuel de Falla, 28-IV-1937; AMF, sig. 7098-062. Carta de Ernesto Halffter a Manuel de Falla, 29-IV-1937; y AMF, sig. 7098-058. Carta de Ernesto Halffter a José María Pemán, 1-X-1937.

${ }^{21}$ Véase "El tenor sevillano Manuel Villalba, en Lisboa", ABC, 23-XII-1936, p. 14. En dicha fuente se indica que el concierto fue a beneficio del ejército español, aunque no hace referencia a que se trate de la inauguración de la temporada del Círculo de Cultura Musical. Véase también Francine Benoit: "Halffter no Circulo de Cultura Musical", Diário de Lisboa, 26-XII-1936, p. 11. casacomum.org/cc/diario_de_lisboa/ (última consulta: 16-12-2015). Citado en I. Contreras Zubillaga: “Obligados a convivir pared con pared'...", p. 31.
} 
Se ha de recordar que, como fue apuntado por Pérez Zalduondo, durante estos años desde el bando sublevado se inició la tendencia de releer parcialmente la música del compositor gaditano. Así, destacando su catolicismo, ascetismo, nacionalismo y sus referencias a Castilla, e ignorando los aspectos más vanguardistas de su obra, se intentó conciliar con la ideología del nuevo Régimen la figura del que por entonces era el compositor español más prestigioso e internacional del momento, intentando aprovecharse de su reputación para conseguir propaganda internacional ${ }^{22}$. No sorprende, por tanto, la interpretación de obras como El retablo de maese Pedro, evento que fue calificado como acontecimiento musical de alta categoría. Sí llama la atención, sin embargo, el hecho de que fueran interpretadas La corza blanca y La niña que va al mar, que, aunque no fuera especificado en la prensa, eran dos canciones sobre poemas de Rafael Alberti, poeta andaluz afecto al bando republicano y que, en estos momentos, ya formaba parte de la Alianza de Intelectuales Antifascistas.

Por las cartas enviadas a Norberto Almandoz, se conoce que Halffter puso gran empeño en conseguir la participación del tenor sevillano ManuelVillalba, considerando el evento como una gran oportunidad artística y diplomática para introducirse tanto en la vida musical del país como en la alta sociedad portuguesa:

[...] no se pueden olvidar las actuales circunstancias y del concierto que se trata: un festival de obras de Falla y propias, inauguración de la temporada, a la que están invitadas las autoridades, cuerpo diplomático, etc. El concierto será radiado. Creo que por nuestro propio interés no debemos poner demasiadas dificultades [...]. La Presidenta del Círculo de Cultura Musical -Sociedad organizadora del conciertotendrá aVillalba a vivir en su casa, lo mismo que a Sarobe y su señora; es la señora Dña. Elisa de Souso Pedroso, perteneciente a una de las mejores familias portuguesas, gran artista y excelente pianista, que tiene un magnífico palacio por donde desfilan constantemente todos los nombres ilustres de las Artes y las Letras que visitan Lisboa. Es una de las grandes amigas de nuestra España ${ }^{23}$.

La prensa sevillana destacó que, junto a la soprano portuguesa Elsa Penchi Levy, se hubiera invitado al "simpático y conocido" tenor sevillano Manuel Villalba en una ocasión que daba pie a enaltecer "la cordialidad lusitano-hispana" 24 . Este cantante, que fue además falangista y combatiente

22 Las publicaciones de Pérez Zalduondo aportan cuestiones fundamentales sobre la reinterpretación parcial e interesada de la música de Manuel de Falla y del empleo de su prestigio para obtener propaganda internacional. Véase G. Pérez Zalduondo: "El nacionalismo como eje de la política musical del primer gobierno regular de Franco (30 de enero de 1938 - 8 de agosto de 1939)", Una música para el Nuevo Estado..., p. 31; id.: "Formulación, fracaso y despertar de la conciencia en la música española durante el franquismo (1936-1958)", Una música para el Nuevo Estado..., p. 202.

${ }^{23}$ Eresbil, sig. A1/L-160. Carta de Ernesto Halffter a Norberto Almandoz, 1-XII-1936.

${ }^{24}$ Véase "El tenor sevillano Manuel Villalba, en Lisboa", ABC, 23-XII-1936, p. 14. 
del bando franquista, adquirió gran renombre durante la Guerra Civil por su participación en múltiples conciertos benéficos y patrióticos celebrados en Sevilla. Además, formó parte del Teatro Lírico de Falange, presentado en abril de 1938, con el que actuó en provincias como Córdoba ${ }^{25}$.

Por tanto,Villalba, al igual que otros intérpretes como José Cubiles o Regino Sainz de la Maza, fue uno de los músicos falangistas que durante estos años desplegó una intensa actividad en las ciudades bajo el dominio del bando sublevado, poniendo así su arte al servicio de Falange y del nuevo Estado. Como ya fue apuntado por Pérez Zalduondo, en periódicos falangistas de la época era muy común definir a estos músicos falangistas como héroes que portaban instrumentos en lugar de armas, algo que ya se había dado en otros regímenes totalitarios ${ }^{26}$. Esto mismo ocurrió en la prensa hispalense con Villalba, quien además había luchado en las filas del bando sublevado, lo que le llevó a ser calificado de "heroico soldado de la Cruzada"27.

De hecho, cuando Halffter quedó separado de su puesto del Conservatorio, fue sustituido en la dirección de la Orquesta Bética de Cámara por Manuel Navarro y, puntualmente, por uno de estos músicos falangistas: el pianista José Cubiles, que en estos años se puso al mando del Departamento de Música de la Delegación de Prensa y Propaganda de Falange Española Tradicionalista y de las Juntas de Ofensiva Nacional Sindicalista (FET y de las JONS) ${ }^{28}$. En los años del conflicto bélico, esta agrupación protagonizó múltiples eventos culturales, poniendo así su música al servicio de la nueva ideología y del nuevo régimen. Esta omnipresencia en la vida musical sevillana y del bando nacional conduce a la idea de que, al igual que se hizo con el prestigio del propio Manuel de Falla, el incipiente estado intentó aprovecharse de la popularidad que había adquirido la orquesta por él creada,

25 Sobre la actividad de este tenor durante la Guerra Civil, véase, por ejemplo: "Para el Aguinaldo del Soldado. La función de gala en homenaje a las naciones amigas", ABC, 12-XII-1937, p. 20; "Para el Aguinaldo del Soldado", ABC, 26-XII-1937, p. 27; "El Miserere de Eslava", ABC, 31-III-1938, p. 15; "Función homenaje", ABC, 16-VI-1938, p. 14; o "Beneficio de Lecturas para el Soldado", ABC, 21-II1939 , p. 19.

${ }^{26}$ Pérez Zalduondo ya informó sobre la existencia de una serie de músicos falangistas que, desde la organización del primer gobierno de Franco en enero de 1938, desplegaron una intensa actividad en las ciudades ya tomadas por el ejército franquista, poniendo su arte al servicio de Falange y del Estado. De nuevo, en el caso de Sevilla se presentan evidencias de estos hechos desde el inicio de la Guerra Civil. Véase G. Pérez Zalduondo: "Formulación, fracaso y despertar en la conciencia crítica...", p. 204; id.: "Music, Totalitarian Ideologies, and Musical Practices under Francoism (1938-1950)", Diagonal, 7, 2011, pp. 34. http://www.cilam.ucr.edu/diagonal/issues/ 2011/Gemma.pdf (última consulta: 24-5-2016); id.: "La música en la revista Vértice (1937-1946)", Una música para el Nuevo Estado..., pp. 68-82.

27 Véase "La función de mañana en San Fernando", ABC, 19-II-1939, p. 21.

28 Aunque Acker apuntó que en tiempos de guerra el compositor siguió dirigiendo dentro y fuera de Sevilla la Orquesta Bética de Cámara, lo cierto es que el compositor no volvió a Sevilla ni intervino en ninguna de las actuaciones de esta agrupación durante el conflicto bélico. Véase Y. Acker: "Ernesto Halffter (1905-1989)...", p. 65; y O. García López: La música en Sevilla durante la Guerra Civil..., pp. 4951, 61-66, 126-128, 134 y 166. 
empleándola como herramienta de propaganda de su nueva política cultural $^{29}$. No obstante, a pesar de que Halffter no volvió a dirigir a dicha orquesta, sus obras tuvieron mucha presencia en los conciertos en los que esta fue dirigida por Cubiles, así como en los que el pianista realizó en solitario (Ilustración 1) ${ }^{30}$.

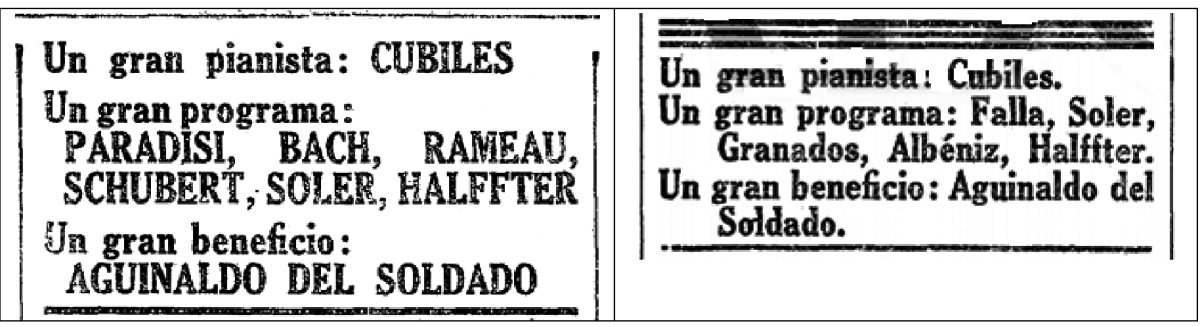

Anuncios publicados en ABC de Sevilla (10-XII-1938 y 22-XII-1938)

Por otra parte, en su puesto de director del Conservatorio, Halffter fue sustituido por el organista de la catedral hispalense Norberto Almandoz, que desempeñó un papel fundamental durante la Guerra Civil tanto por ambos cargos como por sus críticas musicales publicadas en el diario $A B C$ de Sevilla ${ }^{31}$. Liderada por este sacerdote desde el inicio del conflicto, este centro demostró su apoyo al bando sublevado, asistiendo, participando y organizando múltiples actos a favor de su ejército y afines a la ideología del nuevo régimen. Destacan especialmente las conexiones existentes entre la Iglesia y esta institución, que, dirigida por el canónigo Almandoz, participó en la restauración de la vida religiosa que se pretendía en toda la zona nacional ${ }^{32}$.

Los estudiantes portugueses en Sevilla: visita del Orfeón Académico de Coímbra y la Orquesta Aldrabófona

Durante la Guerra Civil española tuvieron lugar intercambios culturales entre intelectuales y universitarios franquistas y salazaristas en España y Portugal, que, en opinión de Pena Rodríguez, sirvieron al bando nacional

\footnotetext{
29 O. García López: La música en Sevilla durante la Guerra Civil..., pp. 60-63, 80-81 y 126-128.

30 Especialmente sus danzas del ballet Sonatina. Véase "Informaciones musicales. Concierto de la Orquesta Bética", ABC, 8-V-1938, p. 18; Norberto Almandoz: "Triunfo de la Orquesta Bética en San Sebastián", $A B C, 31-V I I I-1938$, p. 13; "Un gran pianista", $A B C, 10-X I 1-1938$, p. 12; y "Un gran pianista", ABC, 22-XII-1938, p. 14.

${ }^{31}$ Sobre la labor de Norberto Almandoz en Sevilla, véase O. García López: Norberto Almandoz (18931970), de norte a sur. Historia de un músico en Sevilla, Sevilla, Libargo, 2015.

32 Véase, por ejemplo, A. [Norberto Almandoz]: "La festividad de Santa Cecilia y el concierto de los alumnos del Conservatorio", ABC, 24-XI-1936, p. 18.
} 
para encontrar "un reconocimiento exterior a sus doctrinas por parte de prestigiosas autoridades académicas". Dentro de este intercambio intelectual, se organizaron viajes de estudiantes universitarios al territorio sublevado, que contaron con el apoyo y propaganda de los medios de comunicación lusos, y constituyeron un efectivo instrumento de propaganda del Estado Novo portugués en España, a la vez que una ayuda al bando franquista para conseguir el reconocimiento de la sociedad lusa ${ }^{33}$.

La asociación de estudiantes de la Universidad de Coímbra organizó dos caravanas de ayuda humanitaria con destino a Sevilla, de las cuales resulta especialmente relevante la primera, que partió el 5 de febrero de $1937^{34}$. Ambas fueron coordinadas por el capitán Jorge Botelho Moniz (Ilustración 2), que se convirtió en uno de los principales propagandistas de la causa del fascismo ibérico contra el gobierno democrático de Madrid, y que no tardó en poner su emisora, Rádio Club Português, al servicio del general Franco, iniciando una campaña contra la Segunda República española de gran relevancia en el curso del conflicto bélico ${ }^{35}$. De hecho, esta estación radiofónica organizó otros cinco comboyes humanitarios a la España franquista que tuvieron una enorme proyección propagandística en las sociedades portuguesa y española ${ }^{36}$.

Esta caravana portaría donativos destinados exclusivamente al Ejército del Sur, por lo que, antes de partir, la prensa lusa llevó a cabo una efusiva campaña de propaganda con el fin de que los portugueses se solidarizaran con la misión humanitaria de los universitarios. Este evento consiguió centrar la atención informativa del país luso, pues, además de retratos de figuras como Queipo de Llano y Franco, se publicaron múltiples noticias y mensajes de los estudiantes portugueses, algunos de ellos dirigidos al propio Queipo de Llano, en los que manifestaban su adhesión al bando nacionalista, que consideraban salvador de la civilización cristiana y redentor de la patria ${ }^{37}$.

Por su parte, los rotativos sevillanos no fueron menos, y realizaron también una ingente labor publicitaria con continuas alusiones a este acontecimiento, en las que se mostraban enormemente agradecidos a los estudiantes portugueses, así como al diario $A$ Voz por su campaña propagandística y al capitán Botelho Moniz y a su Rádio Club Português

\footnotetext{
33 A. Pena Rodríguez: Galicia, Franco y Salazar..., pp. 105 y 110.

${ }^{34}$ La segunda caravana partió el día 30 de mayo de 1937 y llegó a Sevilla el día 31. Véase "Ayer llegó a Sevilla la caravana automovilista de estudiantes portugueses que traen donativos para el Ejército", ABC, 1-IV-1937, p. 10.

35 A. Pena Rodríguez: "Sintonía de combate. La propaganda del Rádio Club Português en la Guerra Civil española (1936-1939)”, Historia crítica, 58, 2015, pp. 95, 98, 99.

${ }^{36}$ A. Pena Rodríguez: "Sintonía de combate...", p. 110.

37 Véase A. Pena Rodríguez: Galicia, Franco y Salazar..., p. 110-111.
} 
por los servicios prestados a la causa nacional ${ }^{38}$.

Hay que tener presente que el dinamismo y alcance de los discursos del capitán Botelho Moniz emitidos por el Rádio Club Português -similares a los pronunciados por Queipo de Llano desde Radio Sevilla-, su papel en el campo de batalla al mando de la Misión Portuguesa en España y las acciones propagandísticas contra los republicanos le habían granjeado el reconocimiento general del bando sublevado $^{39}$. Esta visita ofrecía, por tanto, una oportunidad idónea para agradecer a la estación radiofónica y a su presidente la intensa campaña de propaganda franquista que habían llevado a cabo desde el inicio de la contienda. En consecuencia,

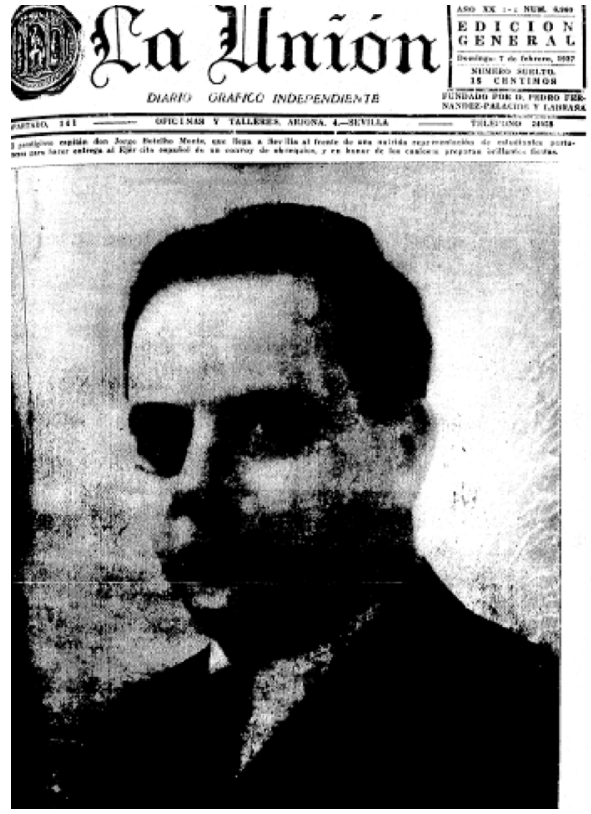

Portada de La Unión, 7-II-1937, dedicada a Jorge Botelho Moniz en una carta enviada a Botelho Moniz, que fue publicada por la prensa hispalense, Queipo de Llano agradeció la nueva prueba de generosidad del país vecino, ensalzando una serie de símbolos afines a ambas naciones como la raza y la religión, y afirmando que estas se encontraban en esos momentos más unidas que nunca debido a la "epopeya gloriosa" que, en opinión del militar, se realizaba en España $a^{40}$.

Además, al igual que ocurrió en los diarios portugueses, en los hispalenses también se publicaron retratos de las autoridades del país vecino, tales como los de Jorge Botelho Monis, António de Oliveira Salazar o el general António Óscar de Fragoso Carmona (Ilustración 3) ${ }^{41}$. Asimismo, dejaron también constancia de la celebración de numerosos actos en Portugal a beneficio de este convoy, tales como el recital de arte a favor de los heridos del bando nacional, organizado por la comisión de señoras de Oporto y los señores Duarte Barredao y el doctor Luis González Cerqueira en el Teatro Gil

38 Véase por ejemplo "El Convoy de Estudiantes Portugueses. ¡Viva la Juventud Portuguesa!”, El Correo de Andalucía, 7-II-1937, p. 3. Este artículo reproduce un texto publicado por J. Fernando de Souza, director de A Voz, en dicho periódico.

${ }^{39}$ C. Oliveira: Salazar e a Guerra Civil de Espanha..., pp. 243-263; y A. Pena Rodríguez: "Sintonía de combate...", pp. 101, 102, 107

${ }^{40}$ Véase "Comunicación oficial del Excelentísimo Señor General Jefe del Ejército del Sur", ABC, 14I-1937, p. 10 


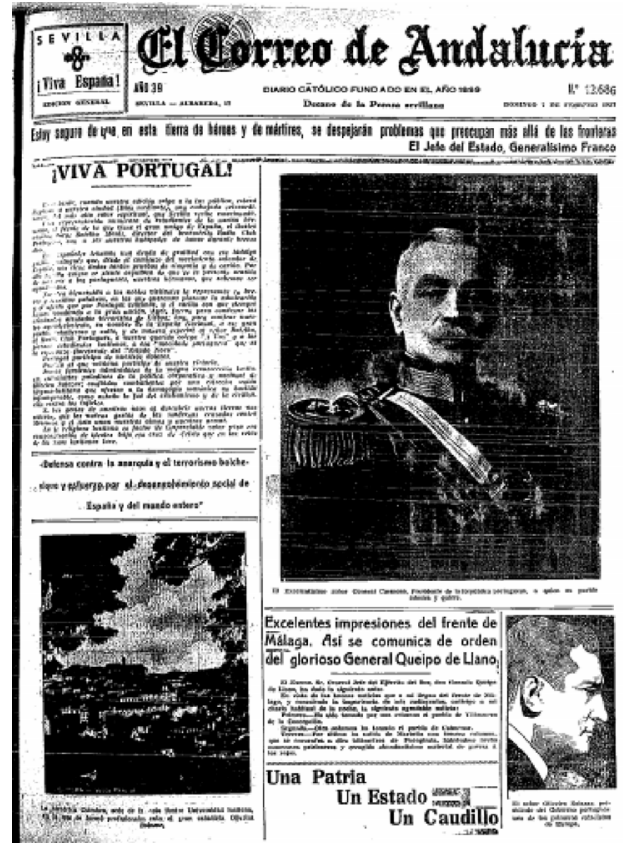

Portada de El Correo de Andalucía, 7-II-1937, con imágenes del general Carmona, de Coimbra y de Salazar
yVicente y en el Palacio de Cristal de Oporto, que según la prensa constituyó un gran éxito ${ }^{42}$.

De esta forma, se instó a los sevillanos a corresponder, en nombre de la España nacional, a estas muestras de gratitud del país hermano. Puntualmente, se fueron publicando en la prensa las distintas iniciativas que se iban acordando para la recepción de los estudiantes portugueses, tales como el nombramiento de Botelho Moniz como Huésped de Honor de la ciudad o la decisión de que los portugueses fueran hospedados en las mejores mansiones de Sevilla ${ }^{43}$. Además, Queipo de Llano dispuso una comisión para organizar la recepción y los actos en honor de los estudiantes portugueses, los cuales contaron con una partida de 3000
fuentes conservadas ponen de mapesetas del presupuesto municipal. Las fuentes conservadas ponen de ma-
nifiesto la minuciosidad con que se preparó el engalanamiento de las calles y la invitación de autoridades para el acto de bienvenida, pruebas del deseo de que este estuviese a la altura de la labor realizada por el país vecino desde el inicio del conflicto bélico ${ }^{44}$.

Finalmente, la comitiva estuvo constituida por 515 personas, en su mayoría alumnos de las Universidades de Coímbra, Lisboa y Oporto y de

${ }^{41}$ Véase La Unión, 7-II-1937, p. 1; El Correo de Andalucía, 31-I-1937, p. 12; El Correo de Andalucía, 7-II-1937, p. 1; y "El ilustre capitán Botelho", El Correo de Andalucía, 10-II-1937, p. 1. La primera de las referencias hemerográficas alude a una página en la que pueden observarse fotografías de António de Oliveira Salazar, Francisco Franco, José Antonio Primo de Rivera, Adolf Hitler y Benito Mussolini. Estos dos últimos son definidos como "la pareja de estadistas geniales", apuntando que "cabe a Mussolini el honor de haber sido el primer Caudillo contra la barbarie comunista y el iniciador de una nueva Edad Histórica".

42 Véase "Diversos actos estudiantiles en Portugal a beneficio del convoy para el Ejército español", ABC, 31-I-1937, p. 14; y "Se celebran en Portugal diversos actos estudiantiles a beneficio del convoy para nuestro glorioso Ejército”, El Correo de Andalucía, 31-I-1936, p. 3.

${ }^{43}$ Véase "El capitán Botelho Monis huésped de honor de la ciudad", El Correo de Andalucía, 5-II1937, p. 05; "La llegada del capitán Botelho Monis y del convoy automovilista de los estudiantes portugueses a Sevilla", El Correo de Andalucía, 6-II-1937, p. 8; y "Ante la próxima llegada del convoy automovilista portugués", El Correo de Andalucía, 6-II-1937, p. 2.

${ }^{44}$ Véase Archivo Municipal de Sevilla, Negociado de Feria y Festejos, Caja 696. Expediente instruido con motivo de la visita a esta ciudad de una expedición organizada por estudiantes portugueses. 
enseñanzas medias, que viajaron en 105 camiones de víveres y automóviles particulares. Junto a ellos viajaron dos agrupaciones musicales portuguesas: el famoso Orfeón Académico de Coímbra, constituido por ciento veinte músicos, que fue calificado por la prensa hispalense como el más importante del mundo, y la Orquesta Aldrabófona, integrada por treinta ejecutantes ${ }^{45}$. Una vez en Sevilla, todos ellos disfrutaron de un apretado programa de actividades cargadas del simbolismo propagandístico de la visita. En palabras de Pena Rodríguez, durante estos días "se sumergieron en la 'cruzada' franquista para transmitir al pueblo español su deseo de ver una España resurgida y en orden, tal y como la estaba construyendo el general Franco" 46.

La ciudad se hallaba engalanada y perfectamente iluminada para recibir a los huéspedes el día 6 de febrero, y los sevillanos, que se vistieron con sus mejores galas, ocuparon la Plaza Nueva y las calles adyacentes, presentando todas ellas un animadísimo aspecto. La comitiva portuguesa fue recibida por las autoridades militares, religiosas, civiles y universitarias en el Ayuntamiento, donde se habían colocado micrófonos que permitiesen la perfecta audición de los discursos de Botelho Moniz, Gutiérrez de Tovar -en representación de Queipo de Llano-, del rector Mota Salado y del alcalde Ramón de Carranza. Este evento, cargado de propaganda salazarista y franquista, estuvo amenizado por el Himno de Portugal y la Marcha Real, que fueron seguidos de ovaciones y vítores, dando lugar, según la prensa hispalense, a un momento de emoción indescriptible. Posteriormente, en la Plaza de San Fernando se hizo entrega de los cincuenta camiones que transportaban los donativos del país luso, que fueron conducidos a la Plaza de la Maestranza por unas calles que habían sido adornadas con banderas portuguesas y españolas para la ocasión ${ }^{47}$.

Al día siguiente, asistieron a una misa en la Iglesia de la Universidad oficiada por el obispo de Málaga, Balbino Santos Oliveras, con objeto de honrar a la Virgen de la Esperanza Macarena y rendir homenaje a los estudiantes fallecidos durante la guerra. Sin duda, la participación del obispo

\footnotetext{
45 Véase "La próxima llegada a Sevilla de la caravana automovilista de estudiantes portugueses, con obsequios para el Ejército nacional", La Unión, 30-I-1937, p. 14; "Diversos actos estudiantiles en Portugal a beneficio del convoy para el Ejército Español", ABC, 31-I-1937, p. 14; "Se celebran en Portugal diversos actos estudiantiles a beneficio del convoy para nuestro glorioso Ejército", El Correo de Andalucía, 31-I-1936, p. 3; "Sevilla, en nombre de España, tributó un grandioso recibimiento a los estudiantes lusitanos", El Correo de Andalucía, 7-II-1937, p. 12. Sobre la Orquesta Aldrabófona, véase también Aníbal Gamboa: "Aldrabófona", El Correo de Andalucía, 11-II-1937, p. 2.

${ }^{46}$ Véase A. Pena Rodríguez: Galicia, Franco y Salazar..., p. 111.

${ }^{47}$ Véase "La llegada del capitán Botelho Monis...", El Correo de Andalucía, 6-II-1937, p. 8; y "Sevilla, en nombre de España...", El Correo de Andalucía, 7-II-1937, p. 12. Los discursos fueron parafraseados con todo detalle en "Anoche llegó a Sevilla la ilustre Comisión portuguesa que preside el eminente capitán Botelho", La Unión, 7-II-1937, p. 19.
} 
malagueño, un día antes de la toma de Málaga por el ejército de Queipo de Llano, no era casual, pues era una forma de hacer eco de su regreso de Tánger, a donde había tenido que huir ayudado por un cónsul italiano al inicio de la Guerra Civil. Tampoco lo era el homenaje a la Virgen de la Esperanza Macarena, cuyo altar había sido incendiado por grupos que se opusieron al golpe militar. La utilización de estos elementos fue parte de la propaganda destinada a descalificar al bando republicano y justificar la lucha del bando nacional, pretendiendo conseguir con ello las simpatías de los países extranjeros y de los desafectos o poco convencidos en el territorio nacional ${ }^{48}$.

En este acto intervinieron profesores del Conservatorio de Música y el Orfeón Académico de Coímbra, interpretando composiciones religiosas. Asistieron también estudiantes del SEU, profesores y el rector de la Universidad, entre otras autoridades civiles. A continuación, se trasladaron al edificio de la Universidad, donde los estudiantes portugueses bailaron algunas danzas típicas a los acordes de los coros lusitanos, correspondiendo las jóvenes hispalenses danzando las sevillanas. Tras la visita a los museos Provincial y Arqueológico, y de una recepción por autoridades sevillanas, concurrieron a un colmado desfile de Flechas y Pelayos y a una Fiesta andaluza en el Andalucía Palace que contó con la participación de un cuadro flamenco y de la Orquesta Sáenz ${ }^{49}$. También en ese día, la Orquesta Aldrabófona, respaldada por el clamoroso éxito obtenido en las numerosas audiciones ofrecidas desde el Rádio Club Português, ofreció un concierto desde el estudio de Radio Sevilla, que, según la prensa, fue también muy celebrado por los radioyentes ${ }^{50}$.

El día 8 de febrero continuaron visitando el Archivo de Indias, la Catedral, y el Palacio Arzobispal, donde fueron recibidos por el cardenal Eustaquio Ilundain y Esteban, que dedicó frases de gratitud a Botelho Moniz y a los jóvenes portugueses, mostrando gran satisfacción por la visita de estos hombres tan cristianos y simpatizantes y defensores del bando nacionalista. Fueron distinguidos también con un vino de honor en el Cuartel del Requeté por la Agrupación Escolar Tradicionalista, en un encuentro que fue amenizado por la Banda de Música del Requeté, que interpretó

\footnotetext{
${ }^{48}$ Sobre la descalificación del bando republicano en la prensa sevillana, véase Concha Langa Nuño: "De republicanos a rojos. La imagen de la República en la prensa nacional durante la Guerra Civil (el caso de ABC de Sevilla)", La comunicación durante la Segunda República y la Guerra Civil, Antonio Checa Godoy, Carmen Espejo Cala, Concha Langa Nuño y Miguel Vázquez Liñán (eds.), Madrid, Fragua, 2007, pp. 450-471.

49 Véase "La llegada del capitán Botelho...", El Correo de Andalucía, 6-II-1937, p. 8; "Hermandad de la Macarena", El Correo de Andalucia, 6-II-1937, p. 11; "La estancia de los estudiantes portugueses en Sevilla", La Unión, 8-II-1937, p. 10; "En la Iglesia de la Universidad", El Correo de Andalucía, 9-II-1937, p. 5; y "Misa ante el altar de la Virgen de la Macarena", ABC, 9-II-1937, p. 13.

${ }^{50}$ Véase "Los actos de mañana", El Correo de Andalucía, 7-II-1937, p. 06.
} 
escogidas composiciones, tales como el Himno de Portugal, el Himno de Falange, el Oriamendi y Boinas Rojas. Por último, se organizó una fiesta que contó con la participación de las Margaritas, que, según la prensa, entusiasmaron a los visitantes bailando las clásicas sevillanas, finalizando el acto dando vivas a España, a Portugal, a Franco, a Queipo de Llano y al Ejército español ${ }^{51}$.

Se observa, por tanto, la importancia que ostentan los himnos por su capacidad de exaltación patriótica y de ideologización, ya que, convertidos en un símbolo más de la Patria, tuvieron una presencia constante en los diversos actos celebrados durante estos años ${ }^{52}$. De la misma forma, ocupa también un lugar relevante el baile por sevillanas, pues en estos años adquirió relevancia la revitalización del folklore, entendido como un símbolo identitario de nuestra raza o modo de $\operatorname{ser}^{53}$.

Ese mismo día por la noche, tuvo lugar un concierto a beneficio del ejército español en el Coliseo España, en el que intervino el Orfeón Académico de Coímbra, dirigido por Raposo Marques, y la Orquesta Aldrabófona, especializada en música popular portuguesa. Se interpretaron piezas religiosas de Gounod, Palestrina,Victoria y de compositores portugueses como Elías de Aguilar y el propio director de la agrupación, así como fados y otras canciones portuguesas. El evento, al que asistieron mutilados o heridos de guerra y altos mandos facciosos como Queipo de Llano, se convirtió en un acto político cargado de simbolismo y de muestras de adhesión entre la dictadura salazarista y el bando nacionalista. Prueba de ello son los discursos pronunciados por el falangista sevillano Manuel Hidalgo y por el director del citado orfeón, los cuales ensalzaron la aproximación afectuosa que se venía desarrollando entre ambas naciones ibéricas ante la necesidad de "defender, en propio bien y mirando por el futuro del mundo entero, en contra de la barbarie de los sin Dios, los postuladores que ennoblecieron a la Humanidad" 54 .

51 Véase "Los actos de mañana", El Correo de Andalucía, 7-II-1937, p. 6; "De la estancia en Sevilla de los estudiantes portugueses", ABC, 9-II-1937, p. 13; "La llegada del capitán Botelho Monis...", El Correo de Andalucía, 6-II-1937, p. 8; "La estancia de los estudiantes portugueses en Sevilla", La Unión, 9-II-1937, p. 12; y "Agasajo a los estudiantes portugueses en el cuartel del Requeté", El Correo de Andalucía, 10-II-1937, p. 2

52 Pérez Zalduondo y Cabrera García ya apuntaron que la importancia de estas piezas musicales no radicaba en su valor musical, sino en su utilidad, pues constituía una herramienta clave en el proceso de ideologización y fueron considerados como símbolos de la Patria, de igual forma que la bandera y el escudo. Véase G. Pérez Zalduondo y Mª I. Cabrera García: "La llamada del Estado a las artes y a la música. El franquismo: una particular forma de colaboración entre las artes", Correspondencia e integración de las artes. Actas del Congreso Nacional de Historia del Arte (Málaga, 18 al 21 de septiembre de 2002), Juan Antonio Sánchez López e Isidoro Coloma Martín (coords.), Málaga, Ministerio de Ciencia y Tecnología, 2004, vol. 2, p. 644.

53 Véase G. Pérez Zalduondo: "Music, Totalitarian Ideologies, and Musical Practices...”, p. 2.

54 "Función en honor del Ejército de España", El Correo de Andalucía, 10-II-1937, p. 2. 
Como fue frecuente en gran parte de actos oficiales y homenajes en los que hubo representación de Portuga ${ }^{55}$, no faltaron en este evento los vítores clamorosos a ambos países y a figuras relevantes como Salazar, Franco o Queipo de Llano, ni tampoco la audición de los himnos de Falange y de la nación amiga, que, según la prensa, escuchados de pie y con la mano extendida, "motivaron un gran desbordamiento de patriotismo" 56.

Los estudiantes portugueses visitaron también el Alcázar, el Parque de María Luisa, los hospitales donde atendían a los soldados heridos, hablaron a través de Radio Sevilla y asistieron a una cena de gala con Queipo de Llano, así como a su nombramiento como Hijo adoptivo y predilecto de Se$v_{i l l a}{ }^{57}$. El 9 de febrero se celebró en el Teatro Lloréns una función de homenaje a los estudiantes portugueses en la cual intervino la Orquesta Aldrabófona y se proyectó una película muda con imágenes del Rádio Club Português, de un desfile de la Juventud portuguesa y de la muerte del general José Sanjurjo. Por si no hubiese quedado suficientemente ensalzada la labor del país vecino, se incluyó un discurso del profesor Manuel Siurot sobre la comunidad espiritual y material de Portugal y España, alabando la labor realizada por Salazar al liberar a su patria de la "amenaza comunista" 58 .

El 10 de febrero el SEU organizó en el Coliseo España una función en honor de los estudiantes portugueses, protagonizada por la ya citada Orquesta Bética de Cámara y La Tarumba. Según la prensa, dicho sindicato había decidido que lo más adecuado para agradecer la labor de la nación hermana era ofrecerle lo que más amaban: su Edad de Oro, interpretándose dos entremeses de uno de los autores literarios más representativos de dicha época, Miguel de Cervantes ${ }^{59}$. Durante la Guerra Civil, en el intento de encontrar el arte más afin al modo de ser genuinamente español, se retomaron los modelos artísticos del pasado, otorgando gran importancia al arte

\footnotetext{
55 Numerosos son los actos oficiales y homenajes de la representación de las naciones amigas, en algunos de los cuales ha quedado constancia en la prensa de la audición de sus himnos. Por ejemplo, en una fecha tan temprana como el 12 de septiembre de 1936, tuvo lugar una función patriótica a beneficio del Ejército sublevado en homenaje a Queipo de Llano. En dicho acto, los Amigos del Libro y del Teatro llevaron a escena la obra teatral El divino impaciente, de José María Pemán, quien pronunció también un discurso. En los descansos, la Banda del Regimiento de Granada interpretó el himno portugués, junto con los "del führer, el del fascismo italiano, el de los Requetés y el de la Falange". Véase "La función patriótica de ayer", ABC, 13-IX-1936, p. 11.

56 "Función en honor del Ejército de España", El Correo de Andalucía, 10-II-1937, p. 2.

${ }^{57}$ Véase "La llegada del capitán Botelho Monis...", El Correo de Andalucía, 6-II-1937, p. 8; "Los estudiantes lusitanos regresan hoy a Portugal", El Correo de Andalucía, 11-II-1937, p. 8; "Hoy será entregado al general Queipo de Llano el título de Hijo adoptivo y Predilecto de Sevilla", ABC, 9-II-1937, p. 13; y "Anoche, el pueblo sevillano tributó un grandioso homenaje de admiración y cariño a su invicto general, señor Queipo de Llano", La Unión, 10-II-1937, p. 13.

58 "Función de Homenaje a los estudiantes lusitanos y al Rádio Club Português", El Correo de Andalucía, 10-II-1937, p. 8; y "La velada en honor de la caravana de estudiantes portugueses", La Unión, 11-III-1937, p. 16.

59 "La Tarumba", El Correo de Andalucía, 7-II-1937, p. 2.
} 
de este periodo de florecimiento cultural y político. De hecho, en el repertorio que esta agrupación teatral universitaria y falangista difundió por la España nacional abundaban las obras del Siglo de Oro y los autos sacramentales. Es más, en opinión de Dennis y Peral Vega, fomentaron un teatro de propaganda al servicio del nuevo Estado y tuvo, al igual que el Teatro Nacional de FET y de las JONS, una labor educadora y depuradora ${ }^{60}$.

En cuanto a la música, la Orquesta Bética, que fue una de las más importantes difusoras de la vanguardia musical en Sevilla, en cuyos programas siempre tuvieron un gran peso el repertorio moderno francés, se limitó ahora a interpretar piezas de Mozart y Boccherini, procedentes de dos naciones amigas, y de Falla, del que ya se ha comentado la relectura parcial que se hizo de su música en estos años ${ }^{61}$. A pesar de que Almandoz se interesó por que en dicho concierto la agrupación estuviera dirigida por Halffter, este excusó no poder ausentarse de Lisboa por los ensayos y preparativos de un concierto a beneficio de la Cruz Roja Española programado para el 17 de febrero de 1937. No obstante, le envió una obra de José Vianna da Mota, director del Conservatorio Nacional de Lisboa, que consideraba debía incluirse en el programa, cosa que finalmente no se hizo, prometiendo además enviar más adelante alguna otra partitura adecuada a la plantilla de dicha orquesta ${ }^{62}$.

Al día siguiente, los estudiantes regresaron a Portugal, aunque, a petición del Círculo de Labradores, la Orquesta Aldrabófona permaneció en Sevilla hasta el 14 de febrero, pudiendo así presenciar la corrida de toros organizada por Falange Española y ofrecer un nuevo concierto desde Radio Sevilla. Además, tuvieron la gentileza de ofrecer el mismo día de su partida un concierto a los acogidos del Hospicio Provincial y Hogar de San Fernando en el que intervino también la Banda de Música Municipal, acción desinteresada y caritativa que fue también elogiada por la prensa hispalense ${ }^{63}$.

\section{La Mocidade portuguesa en la Primera Demostración Nacional de las Organizaciones Juveniles de FET y de las JONS}

A pesar de que Martínez del Fresno ha demostrado los tempranos y continuos intercambios para estrechar lazos amistosos que estableció la Sección

\footnotetext{
${ }^{60}$ Véase Nigel Dennis y Emilio Peral Vega (eds.): Teatro de la Guerra Civil: el bando nacional, Madrid, Fundamentos, 2010. Véase también Luis Escobar: En cuerpo y alma. Memorias, Madrid, Temas de Hoy, 2000; y Berta Muñoz Cáliz: El teatro crítico español durante el franquismo, visto por sus censores, Madrid, Fundación Universitaria Española, 2005.

${ }^{61}$ Véase "La Tarumba y la Bética de Cámara en el Coliseo", ABC, 11-II-1937, p. 12; y "La Tarumba", FE, 31-I-1937, p. 7.

62 Véase Eresbil, sig. A1/L-161. Carta de Ernesto Halffter a Norberto Almandoz, 26-I-1937.

${ }^{63}$ Véase "Orquesta Aldrabófona", ABC, 12-II-1937, p. 18; "Orquesta Aldrabófona", El Correo de Andalucía, 13-II-1937, p. 02; "Una función benéfica por la Aldrabófona", El Correo de Andalucía, 13-II1937, p. 11; y "Teatro San Fernando", El Correo de Andalucía, 14-II-1937, p. 3.
} 
Femenina de FET y de las JONS con las organizaciones femeninas alemanas, italianas y portuguesas durante la Guerra Civil española y los primeros años del Franquismo, lo cierto es que, según los datos analizados hasta el momento, durante la contienda no proliferaron en Sevilla relaciones de este tipo ${ }^{64}$. Constituye una excepción, sin embargo, la Primera Demostración de las Organizaciones Juveniles de FET y de las JONS, celebrada en la capital andaluza, que contó con la presencia de una representación de las Juventudes Femeninas Hitlerianas, de las Mocidade Portuguesas y de los Flechas de Marruecos. Esta concentración tuvo lugar el 29 de octubre de 1938, día del año que desde 1934 había adquirido la doble significación de conmemoración de la fundación de Falange y Día de los Caídos del partido y que a partir de este momento se convertiría también en el Día de la Juventud (Ilustración 4) ${ }^{65}$.

Desde mediados de octubre la prensa hispalense informó puntualmente de las novedades relativas a este acontecimiento, tales como la llegada de una representación de las Juventudes Femeninas Hitlerianas y de las Organizaciones Juveniles de todas partes de la España nacional ${ }^{66}$. Estos textos intentaban transmitir la idea de una juventud altamente disciplinada y vigilada atentamente por los mandos del partido. Como no podía ser de otra forma, las juventudes se encontraban estrictamente divididas en chicas, que fueron hospedadas en domicilios particulares, y chicos, que se instalaron en un campamento organizado en el Sector Sur de la antigua Exposición Iberoamericana, y donde pasaban el día rezando, entonando cantos patrióticos y ensayando los ejercicios militares y gimnásticos que ejecutarían en la demostración ${ }^{67}$. Otro de los aspectos ensalzados desde las columnas de los diarios fue la grata convivencia vivida durante estos días, siendo definida como una muestra de la hermandad que debía unir a todos los españoles y que unía ya "a todos los de la España liberada"68.

\footnotetext{
${ }^{64}$ Los intercambios culturales de la Sección Femenina de FET y de las JONS con Alemania, Italia y Portugal durante la Guerra Civil y los primeros años del Franquismo han sido tratados en B. Martínez del Fresno: "La Sección Femenina de Falange...", pp. 357-406.

65 Véase Francisco Moret: Conmemoraciones y fechas de la España nacionalsindicalista, Madrid, Ediciones de la Vicesecretaría de Educación Popular, 1942, p. 89; Julián Pemartín: "El 29 de octubre, Día de nuestra Juventud", Arriba, 29-X-1940; Zira Box Varela: La fundación de un régimen. La construcción simbólica del franquismo, tesis doctoral, Universidad Complutense de Madrid, 2008, p. 129.

66 Véase por ejemplo "El jefe nacional de las Juventudes hitlerianas femeninas en Sevilla", FE, 19X-1938, p. 1; "La jefe nacional de las Juventudes femeninas hitlerianas en Sevilla", El Correo de Andalucía, 19-X-1938, p. 5; y "La estancia en Sevilla de la Delegación alemana de Juventudes hitlerianas femeninas", FE, 20-X-1938, p. 7.

${ }^{67}$ Véase "La concentración de Flechas del día 29", El Correo de Andalucía, 19-X-1938, p. 5; "Tres mil flechas y cadetes de todas las regiones de España hacen vida de campamento preparándose para la Primera Demostración Nacional de Organizaciones juveniles en Sevilla", FE, 20-X-1938, p. 6; y "Los mandos de Organizaciones Juveniles en nuestra ciudad”, El Correo de Andalucía, 20-X-1938, p. 1.

68 Véase "Miles de Flechas de toda España se concentran hoy en Sevilla", El Correo de Andalucía, 29X-1938, p. 10.
} 


\section{La Vida es Milicia}
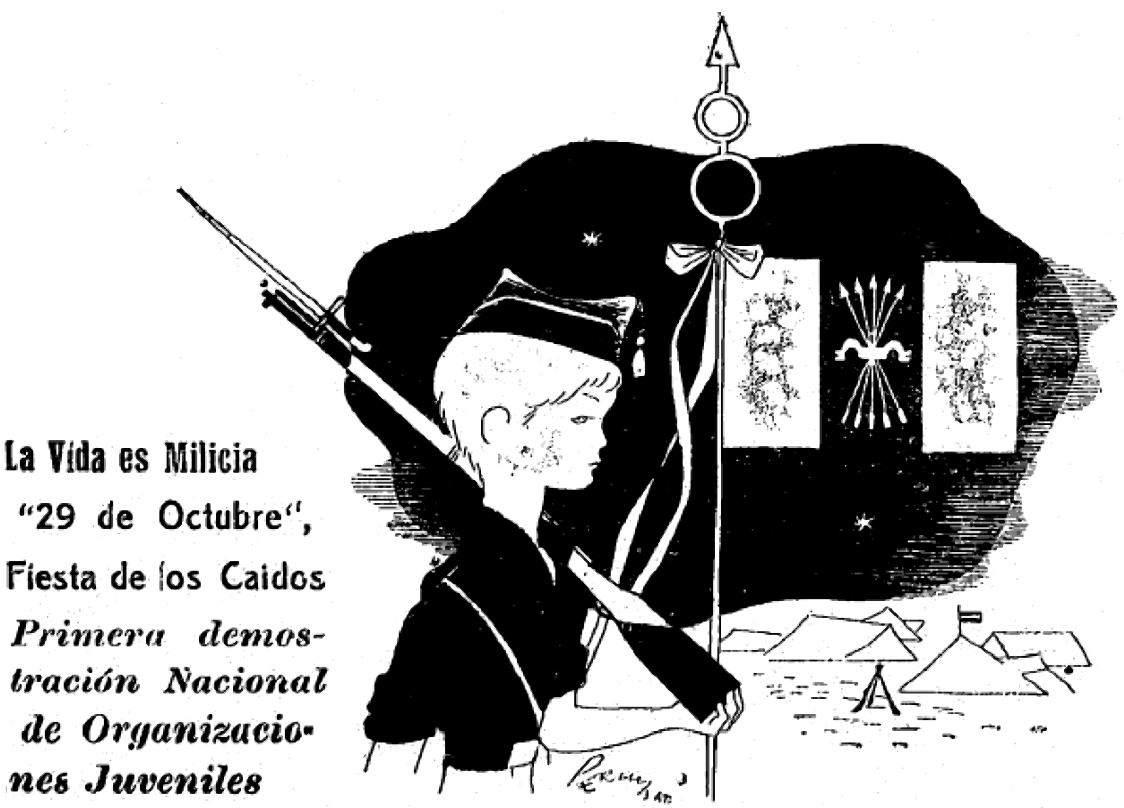

El Correo de Andalucía, 27-X-1938: anuncio de la Primera Demostración de las Organizaciones Juveniles

En dicho campamento se alojó también la Orquestina de los Flechas de Larache, procedentes de Marruecos, que el 25 de octubre ofreció un concierto desde la emisora de Radio Sevilla junto con el Coro de Flechas Femeninas de la Organización Juvenil de Málaga. Al día siguiente, le tocó el turno a los coros de Flechas Femeninas de Lugo y el coro masculino de la Organización de Asturias ${ }^{69}$. Además, se trasladó también a esta ciudad la Agrupación musical de la Organización Juvenil de Zaragoza, que el día de su llegada desfiló por las calles de la ciudad interpretando composiciones marciales ${ }^{70}$.

Las muchachas ensayaron también sin descanso los bailes regionales que habían aprendido en los campamentos de verano y que serían ofrecidos al público el día 29. Las sevillanas habían preparado para la ocasión varios bailes andaluces, que fueron montados en los salones de la Sección Femenina de FET y de las JONS de la calle Albareda por Joaquín Quiñones. La prensa destacó también la compenetración existente entre las muchachas, y el

${ }^{69}$ Véase "La orquesta de O. J. de Larache llegó esta mañana", FE, 21-X-1938, p. 6; y "La concentración de Organizaciones Juveniles", FE, 25-X-1938, p. 6; "Emisión de radio dedicada a las Organizaciones Juveniles", La Unión, 25-X-1938, p. 9; "Las Organizaciones Juveniles para la Concentración del día 29", El Correo de Andalucía, 26-X-1938, p. 5; y "Nuevas emisiones de radio", FE, 27-X-1938, p. 6.

70 "La concentración de Organizaciones Juveniles. Notas de la jornada de ayer", FE, 27-X-1938, p. 6; y "Desfile de los Flechas de Marruecos por las calles céntricas", FE, 27-X-1938, p. 6. 
interés por aprender los bailes de otras regiones, por lo que, en los momentos de descanso, ellas mismas se los enseñaban por su cuenta ${ }^{71}$.

El acto, que congregó entre 15.000 y 18.000 jóvenes (Ilustración 5), se inició con una solemne misa de campaña ante una monumental cruz que había sido instalada en el estadio ${ }^{72}$. Siguió el discurso, radiado a toda España, de Raimundo Fernández Cuesta, Secretario General del Movimiento y Ministro de Agricultura.A continuación, tuvo lugar la demostración de los Flechas, en los que participaron un total de 6.000 niños y niñas procedentes de las Organizaciones Juveniles de todas las provincias de la España nacional. Finalmente, el evento culminó con un desfile de antorchas ante la Cruz de los Caídos de la Plaza del Triunfo, que fue amenizado por diferentes bandas de música que actuaron en varios momentos a lo largo de la jornada ${ }^{73}$.

La demostración de las Organizaciones Juveniles se inició con la entrada en el estadio, a los acordes del Himno Nacional, de los mandos de Falange ${ }^{74}$. El programa estuvo compuesto por varios números de educación premilitar y educación fisica, una exhibición de Flechas navales, composiciones sobre el terreno de variados rótulos y emblemas alusivos al Movimiento, y una última sección dedicada a cantos regionales, marchas e himnos ${ }^{75}$.

${ }^{71}$ Véase "La concentración del día 29 en Sevilla. Llegada de trenes", El Correo de Andalucía, 20-X-1938, p. 9; "Las Organizaciones Juveniles para la Concentración del día 29", El Correo de Andalucía, 27-X-1938, p. 7; "Organizaciones Juveniles. Flechas Femeninas", El Correo de Andalucía, 27-X-1938, p. 8.

72 Existen discrepancias en cuanto al número total de jóvenes que asistieron al evento. Según el diario FE se reunieron 15000 Flechas. Véase "15000 muchachos se reunirán en la magna concentración Nacional de Organizaciones Juveniles”, FE, 21-X-1937, p. 2. Además, en El Correo de Andalucía fue publicada una tabla del número de Flechas que habían llegado de cada provincia que sumaba un total de 2328 niños y 563 niñas, a los que habrían de sumarles el día de la Demostración 5000 de Sevilla capital, 7000 de la provincia de Sevilla y otros 3000 procedentes de Cádiz, Córdoba y Huelva. Por lo tanto, según este diario la suma también ascendería a casi 15000 jóvenes. Véase "Miles de Flechas de toda España se concentran hoy en Sevilla", El Correo de Andalucía, 29-X-1938, p. 10. No obstante, en este mismo periódico se incluyó el gráfico que reproducimos en el presente artículo, en el que se indica que la cifra total fue de más de 18000 Flechas. Véase El Correo de Andalucía, 29-X-1938, p. 16. Aunque en el documental Juventudes de España, encargado por el Departamento Nacional de Cinematografía a Edgar Neville indique que fueron 30000 los jóvenes que participaron en el evento, la disparidad entre dicha cifra y las apuntadas por la prensa, así como el carácter propagandístico de dicha película ha llevado a desestimar este dato. Sobre este documental, véase Álvaro Matud Juristo: "Edgar Neville: de intelectual republicano a cineasta franquista", Por el precio de una entrada: estudios sobre historia social del cine, Julio Montero Díaz y José Cabeza San Deogracias (coords.), Madrid, Rialp, 2005, pp. 218-221. El documental puede visualizarse en https://www.youtube.com/watch?v=E8ZLiuzkq_E (última consulta: 9-2-2016).

73 Véase "Vendrá a Sevilla el señor Fernández Cuesta", El Correo de Andalucía, 22-X-1938, p. 5; "Miles de Flechas de toda España se concentran hoy en Sevilla", El Correo de Andalucía, 29-X-1938, p. 10; "Caídos por Dios y por España: ¡Presentes! La Primera Demostración Nacional de Organizaciones juveniles se celebra en Sevilla con brillantísimo esplendor. Raimundo Fernández Cuesta, en emocionadas palabras, evoca la gigantesca figura y la obra nacional de José Antonio", FE, 30-X-1938, p. 1; y "El desfile de las fuerzas y organizaciones", ABC, 30-X-1938, p. 11.

74 "Espléndida demostración de nuestras Organizaciones juveniles en el Stadium de la Exposición Iberoamericana. Millares de muchachos hicieron gala de instrucción, armonía y disciplina magníficas", FE, 30-X-1937, p. 3.

75 Véase "Delegación Nacional de Organizaciones Juveniles de FET y de las JONS. Demostración nacional 29 de octubre", FE, 28-X-1938, p. 1. 


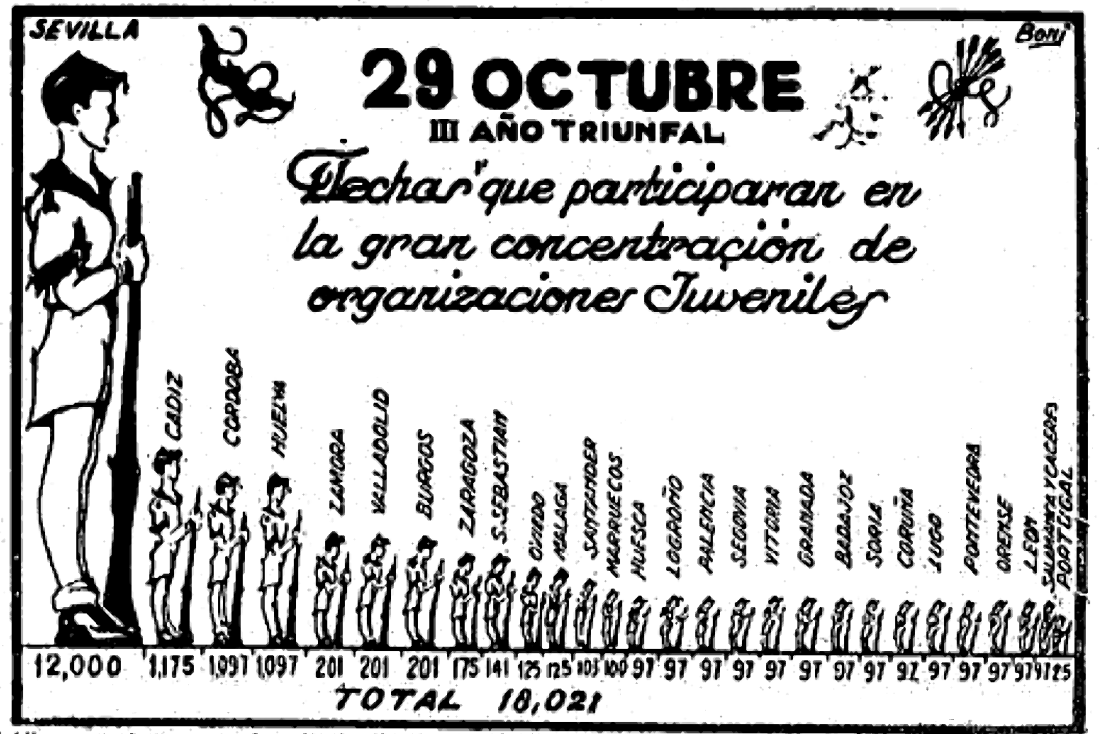

Grálfco on el quo puodon ficil monla observarso las reprosonlacl olles do Organlzagionos Juyentlos do cada provincla--(Dibujo do Boni),

El Correo de Andalucía, 29-X-193): gráfico de las representaciones de cada provincia que tomaron parte en la Primera Demostración de las Organizaciones Juveniles

Por la presencia de música, dos de los números de educación física merecen especial atención. En el primero tomaron parte mil Flechas Femeninas que, al compás de la marcha Bajo la doble águila, del compositor austriaco Josef Wagner, avanzaron desde el lateral en el que se encontraban hasta situarse formando cuatro grandes cuadros. A continuación, realizaron su número de gimnasia rítmica, acompañadas musicalmente por la Orquestina de Larache $^{76}$.

En el segundo, doscientas Flechas Femeninas pertenecientes a las Organizaciones Juveniles de seis regiones distintas (Asturias, Valladolid, Galicia, Santander, Málaga y Sevilla) interpretaron danzas y canciones regionales que habían aprendido en los campamentos ${ }^{77}$. A continuación reproducimos parcialmente textos relativos a dicha actuación publicados en la prensa:

76 "Llega el general Queipo de Llano", FE, 30-X-1938, p. 3. Martínez del Fresno apunta que la gimnasia rítmica estuvo acompañada por "música de estudiantina antigua" y que los grupos de baile avanzaron "de forma conjuntada al ritmo de una dulzaina castellana y un tamboril". No obstante, no se ha encontrado alusión a estos instrumentos en la prensa hispalense consultada. Véase B. Martínez del Fresno: "La Sección Femenina de Falange...", p. 370.

77 "Delegación nacional de Organizaciones Juveniles de las FET y de las JONS. Demostración nacional 29 de octubre", FE, 28-X-1938, p. 1; "Miles de Flechas de toda España se concentran hoy en Sevilla", El Correo de Andalucía, 20-X-1938, p. 10. 
A continuación de estos números vino el de las danzas regionales, ejecutado por 200 flechas femeninos, representantes de seis regiones. Sobre un tablado, situado en medio del field, actuaron las flechas castellanas, asturianas, montañesas, andaluzas, etc. Se bailaron jotas, muñeiras, malagueñas, sevillanas y se cantó por asturianas y fandanguillos, entre grandes aplausos del público. Las muchachas estaban vestidas a la usanza de sus respectivas regiones. Indiscutiblemente este fue un número que agradó mucho $[\ldots]^{78}$.

$* * *$

Terminada esta breve lección, entran en el campo los coros regionales, que visten trajes típicos. Se sitúan en el centro del terreno. Las flechas asturianas, que pertenecen al Campamento de Navia, son las primeras en actuar. Aires de aquella tierra, canciones y bailes, que merecen como premio una cariñosa ovación. Les siguen las flechas vallisoletanas que formaron en el Campamento Femenino de Laredo. Bailan Habas verdes y Jota cruzada, recibiendo igual premio. Galicia está bien representada. Un coro de Flechas de Lugo, acompañado de unos gaiteros.Y suena Baila, nena y Muñeira, donde se lucen con garbo y majeza las flechas gallegas. Reúnen nutridos aplausos. Las flechas de Santander, que asimismo estuvieron en la Colonia-campamento de Laredo, merecen también la aprobación de todos. Sevilla y Málaga ponen fin a los cantos y danzas regionales. Cantan en primer lugar dos nenas con bastante "estilo". Suenan "olés” en honor de las pequeñas. Después, las Flechas de Málaga y Sevilla rivalizan en diversos bailes flamencos, escuchando al final muchos aplausos, que se repiten al retirarse ${ }^{79}$.

Finalmente, la demostración se cerró con cantos, marchas e himnos regionales y patrióticos, tales como el Himno nacional, el Cara al sol y el Oriamendi, que el público escuchó de pie y en posición de saludo fascista ${ }^{80}$. Sin duda, este constituyó un acto cargado de propaganda franquista, al que asistieron altos mandos de FET y de las JONS y periodistas extranjeros como el italiano Federico Fedrichi, el alemán Carlos Brener o el francés Marcel Peter ${ }^{81}$. No obstante, se observa que, a diferencia de lo acontecido durante los primeros meses de la Guerra Civil española, la figura de Queipo de Llano comienza a perder prestigio y a pasar desapercibida en las reseñas periodísticas de este tipo de eventos. Este hecho es comprensible atendiendo a las investigaciones que han apuntado que, desde la constitución del primer gobierno de Franco en enero de 1938, Queipo de Llano fue

78 Véase "La Primera Demostración de las Organizaciones Juveniles, en el Stadium", ABC, 30-XII1938 , p. 12.

79 "Llega el general Queipo de Llano", FE, 30-XII-1938, p. 3.

80 Véase "Llega el General Queipo de Llano", FE, 30-X-1937, p. 1; "La Primera Demostración de las Organizaciones Juveniles, en el Stadium", ABC, 30-XII-1938, p. 12; "Invocación a las juventudes", ABC, 30-X-1938, p. 11; y "Los himnos", La Unión, 30-X-1938, p. 11.

${ }^{81}$ Véase "La Fiesta del Caído. Ante la solemne conmemoración de hoy. El ministro de Agricultura, don Raimundo Fernández Cuesta, en Sevilla", ABC, 29-X-1938, p. 9; "Pilar Primo de Rivera en Sevilla", ABC, 29-X-1938, p. 9; "Periodistas extranjeros", ABC, 29-X-1938, p. 9; "Las Organizaciones Juveniles para la Concentración del día 29", El Correo de Andalucía, 29-X-1938, p. 7; y "Ensayo general de las Flechas", ABC, 29-X-1938, p. 9. 
relegado del poder que ostentaba en la capital andaluza ${ }^{82}$. Indistintamente, la asistencia de personalidades destacadas y de numeroso público, así como la constatación de la capacidad y posibilidades del Movimiento Nacional, llevó a la prensa sevillana a considerarlo un gran éxito ${ }^{83}$.

En lo que respecta a la juventud del país luso, veinticinco fueron los muchachos de la organización Mocidade Portuguesa que asistieron al evento invitados por el Gobierno. Desde la prensa hispalense, se alabó la importancia que Salazar concedía a sus jóvenes en la construcción de su Estado Novo, destinando a ellos lo más sólido y eficaz de su programa. Esta visita se concibió como una oportunidad idónea para admirar la organización y disciplina de los vecinos lusos, así como para establecer relaciones fraternales entre las juventudes de ambos países ${ }^{84}$.

Viajó también a Sevilla Eça de Queiroz, Subjefe Nacional de Prensa de Portugal, que desde el primer momento había manifestado su adhesión al bando nacionalista. La visita constituyó para la prensa hispalense un hecho de gran trascendencia por la propaganda que este haría de cuanto había visto en los frentes y en la retaguardia, así como de la hermandad de ambas juventudes ${ }^{85}$.

No obstante, lejos de los intercambios musicales establecidos con motivo del citado convoy humanitario, en esta ocasión la intervención de la Juventud Portuguesa consistió únicamente en depositar una corona de flores con lazos de las banderas española y portuguesa entrelazadas en la Cruz de los Caídos que había sido instalada en el estadio. Este gesto fue acompañado por el Himno de Portugal a cargo de las bandas de música, siendo éste escuchado por el público con el brazo en alto ${ }^{86}$.

\footnotetext{
82 Es bien sabido que un mes después de la formación del primer gobierno de Franco en Burgos en enero de 1938 cesan las charlas de Queipo de Llano desde los micrófonos de Radio Sevilla. Por otra parte, cabe señalar también su posterior cese y exilio encubierto a Italia al que se vio sometido dicho general. Véase Concha Langa Nuño: "El imperio perdido y recuperado. Propaganda en la prensa franquista durante la Guerra Civil", En torno al "98": España en el tránsito del siglo XIX y XX (Actas del IV Congreso de la Asociación de Historia Contemporánea), Rafael Sánchez Mantero (ed.), Huelva, Universidad de Huelva, 2010, p. 336; Manuel Barrios: El último virrey. Queipo de Llano, Sevilla, Ed. Rodríguez Castillejo, 1990, pp. 202-205.

83 Véase "La Primera Demostración Nacional de las Organizaciones Juveniles", ABC, 30-X-1938, p. 12.

${ }^{84}$ Véase Francisco de Cossío: "España y Portugal", ABC, 1-XI-1938, p. 15; "La Mocidade Portuguesa en la concentración", FE, 28-X-1938, p. 6; "La demostración juvenil de hoy. Llegada de la Mocidade portuguesa", ABC, 29-X-1938, p. 9; "La concentración de Organizaciones Juveniles", El Correo de Andalucía, 29-X-1938, p. 1; "Las Organizaciones Juveniles para la concentración del día 29", El Correo de Andalucía, 29-X-1938, p. 7; y "Miles de Flechas de toda España se concentran hoy en Sevilla", El Correo de Andalucía, 29-X-1938, p. 10.

${ }^{85}$ Francisco de Cossío: "España y Portugal", ABC, 1-XI-1938, p. 15. Sobre la representación de Portugal en dicho evento, véase también "El señor Eça de Queiroz a Sevilla", El Correo de Andalucía, 25-X1938, p. 5; "La Fiesta del Caído. Ante la solemne conmemoración de hoy. Llegada del señor Eça de Queiroz", ABC, 29-X-1938, p. 9; "Llega a Sevilla el Subjefe de Prensa portuguesa, señor Eça de Queiroz", La Unión, 29-X-1938, p. 8.

${ }^{86}$ Véase "Los portugueses", El Correo de Andalucía, 30-X-1938, pp. 6-7; "La representación de las Mocedade portuguesas", La Unión, 30-X-1938, p. 9.
} 
Además, con motivo de la estancia en Sevilla de las Organizaciones Juveniles de las distintas regiones de España y de las Mocidade portuguesas, la Hermandad de la Macarena organizó una solemne Salve ante la Virgen de la Esperanza Macarena, acontecimiento que contó con la colaboración desinteresada de la Orquesta Bética y de un nutrido coro que interpretó composiciones religiosas tales como Letanías y Salve de Hilarión Eslava y el Himno Oficial del Congreso Mariano de Eduardo Torres, que fue cantado por los fieles ${ }^{87}$.

\section{Conclusiones}

A lo largo del presente artículo se ha venido observando que los intercambios culturales que tuvieron lugar entre el franquismo y el salazarismo durante la Guerra Civil española fueron de vital trascendencia para el reconocimiento exterior del Estado Novo portugués y del Nuevo Estado franquista que se estaba configurando, afectando también al desarrollo del conflicto bélico. En el caso de Sevilla, ciudad rápidamente dominada y controlada por el general Queipo de Llano, desde el inicio de la contienda forjó con el pás vecino una amistad basada en la defensa de una causa totalitaria común y apoyada en una serie de elementos afines a ambas naciones como la religión, la raza o el anticomunismo.

En concreto, el análisis de estas relaciones ha puesto de manifiesto la importancia de la música y los músicos como herramientas de propaganda para implantar ideologías acordes a los regímenes totalitarios de ambas naciones. Por las personalidades que asistían y los discursos que incluían, los eventos musicales comentados podrían considerarse verdaderos actos políticos, dedicados a descalificar al bando sublevado y a justificar la necesidad de la Guerra Civil, y de paso ofrecer una imagen del bienestar que se vivía en la zona nacional y de un régimen preocupado por la cultura y el arte. Además, el arte sonoro fue un elemento fundamental a la hora de consolidar los firmes lazos entre la Iglesia y el régimen que caracterizarían al franquismo.

En cuanto a los músicos, se ha constatado la presencia de músicos vinculados a la ciudad de Sevilla pero residentes en Portugal, donde participaron en acciones propagandísticas, como es el caso de Halffter y el concierto a beneficio del Ejército Nacional celebrado en Lisboa. Hubo otros intérpretes sevillanos que, como el falangista ManuelVillalba, se desplazaron al país vecino para actuar en eventos de este tipo.Y existieron también los que, desde la capital andaluza, organizaron e intervinieron en actos

\footnotetext{
${ }^{87}$ Véase "Salve a la Virgen de la Macarena. A ella asistirán las Organizaciones Juveniles", ABC, 29. X-1938, p. 9; "Una Salve a la Virgen de la Esperanza", El Correo de Andalucía, 1-XI-1938, p. 8.
} 
musicales que contarían con la presencia de una representación portuguesa, como ocurrió con Norberto Almandoz y el profesorado del Conservatorio de Música que este dirigía, o con la Orquesta Bética de Cámara. Por otra parte, también hubo agrupaciones portuguesas, como el Orfeón Académico de Coímbra y la Orquesta Aldrabófona que, tomando parte en una campaña benéfica, se desplazaron a la capital andaluza con objeto de celebrar funciones benéficas y propagandísticas a favor del bando nacional.

De esta forma, el tránsito de personalidades, agrupaciones musicales e intérpretes entre los países vecinos se convirtió en el pretexto ideal para la celebración de una serie de eventos artísticos y religiosos que tuvieron un fuerte componente político e ideológico. Así, el arte y el carácter festivo de estas visitas se emplearon conscientemente para congregar a las masas y ofrecerles unos programas estratégicamente confeccionados donde lo musical se entremezclaba con discursos que rozaban el mitin político, películas que ensalzaban el régimen de Salazar y con las obras teatrales del Siglo de Oro español.Y así, en una guerra ideológica como la que vivió España, estos actos culturales dieron pie a desplegar una acusada propaganda, en los que, tomando como banda sonora la música religiosa, los himnos, el folklore o autores como Manuel de Falla, se aplaudió y alabó al Estado Novo portugués y se intentó justificar una sublevación que, tras una cruenta Guerra Civil, dio lugar al Nuevo Estado de Franco.

Recibido: 23-2-2016

Aceptado: 18-5-2016 